\title{
Clinically Undetected Hodgkin Lymphoma Diagnosed Initially on Bone Marrow Biopsy: A Large Retrospective Observational Study from a Tertiary Care Center
}

\author{
Navatha Vangala ${ }^{1}$ Tara Roshni Paul ${ }^{1}$ Shantveer G. Uppin ${ }^{1}$ Megha S. Uppin ${ }^{1} \quad$ G. Sadashivudu ${ }^{2}$ \\ Y. Satyanarayana Raju ${ }^{3}$ M. Nageswara Rao ${ }^{3}$
}

${ }^{1}$ Department of Pathology, Nizams Institute of Medical Sciences,

Address for correspondence Tara Roshni Paul, MD Pathology, Hyderabad, Telangana, India

2 Department of Medical Oncology, Nizams Institute of Medical Department of Pathology, Nizams Institute of Medical Sciences, Hyderabad, Telangana, India (e-mail: troshnip@yahoo.co.in).

Sciences, Hyderabad, Telangana, India

${ }^{3}$ Department of General medicine, Nizams Institute of Medical Sciences, Hyderabad, Telangana, India

Ind J Med Paediatr Oncol 2021;42:554-560.

\section{Abstract \\ Keywords \\ - Hodgkin lymphoma \\ - primary diagnosis \\ - bone marrow biopsy}

Introduction Hodgkin lymphoma (HL) involving the bone marrow (BM) is relatively rare with an incidence ranging from $4 \%$ to $18 \%$. The incidence of primary $\mathrm{HL}$ of marrow is $0.25 \%$. To the best of our knowledge, the present study is the largest study on $\mathrm{HL}$ diagnosed initially on marrow biopsy.

Objective To establish diagnostic criteria based on clinicopathological and histological features in $\mathrm{HL}$ diagnosed first on the marrow.

Materials and Methods This was a retrospective study done from January 2012 to December 2020 that included 36 cases of HL diagnosed initially on BM. Based on the presence of large mononuclear or binucleate Reed-Sternberg (RS)-like cells in a polymorphous inflammatory background, $\mathrm{HL}$ was suspected and immunohistochemistry (IHC) with CD15 and CD30 was done. Correlation with subsequent lymph node biopsies was done, wherever possible.

Results Fever (94.4\%) was the most common symptom, followed by loss of weight (66.7\%). Twenty-one cases (58.4\%) had uni/bicytopenia and 15 cases $(41.6 \%$ ) had pancytopenia. Only one case showed suspicious mononuclear RS cells on aspirates and the rest of the cases were diagnosed on trephine biopsy alone. Trephine imprints showed variable cellularity in $13(36 \%)$ cases. Diffuse involvement was seen in 24 cases (66.7\%), and focal nodular aggregates were seen in 12 cases (33.3\%). Out of 36 cases, 26 cases ( 19 cases on marrow and 7 cases on lymph node) were confirmed as $\mathrm{HL}$ with IHC. Immunophenotype of the RS cells on the marrow was $\mathrm{CD}^{+} 0^{+} / \mathrm{CD} 15^{+}$in $(6 / 29)$ (20.7\%) cases, $\mathrm{CD}^{+} 0^{+} / \mathrm{CD} 15^{-}$in $(7 / 29)(24.1 \%)$ cases and $\mathrm{CD} 30^{-} / \mathrm{CD} 15^{+}$in $(6 / 29)$ $(20.7 \%)$ cases. Seven cases (26.9\%) were diagnosed on subsequent lymph node biopsy
DOI https://doi.org/ 10.1055/s-0041-1740048. ISSN 0971-5851.

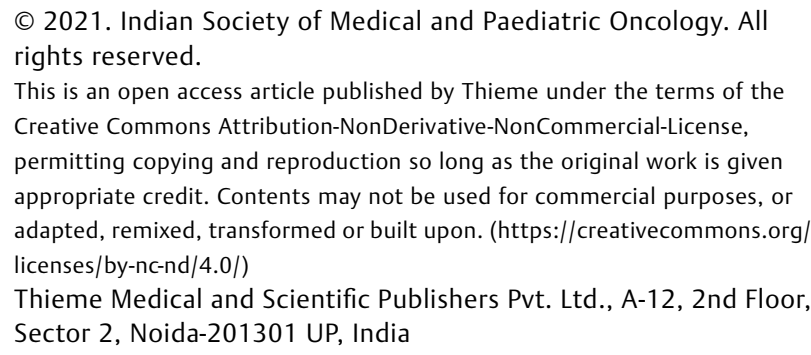

(c) 2021. Indian Society of Medical and Paediatric Oncology. All rights reserved.

This is an open access article published by Thieme under the terms of the Creative Commons Attribution-NonDerivative-NonCommercial-License, permitting copying and reproduction so long as the original work is given appropriate credit. Contents may not be used for commercial purposes, or adapted, remixed, transformed or built upon. (https://creativecommons.org/ licenses/by-nc-nd/4.0/)

Thieme Medical and Scientific Publishers Pvt. Ltd., A-12, 2nd Floor, Sector 2, Noida-201301 UP, India 
as mixed cellularity HL with IHC confirmation. Marrow fibrosis was seen in 16 cases (44.4\%), and granulomas were seen in 8 cases (22.2\%).

Conclusion In cases presenting with long-standing fever and cytopenias, HL must always be suspected, even if there are no palpable lymph nodes. Bone marrow biopsy is preferable over aspiration in such cases and IHC plays a major role in diagnosing the cases.

\section{Introduction}

Hodgkin lymphoma (HL) is a malignant lymphoid neoplasm usually involving the lymph nodes. HL infiltrating bone marrow (BM) is relatively rare with an incidence ranging from $4 \%$ to $18 \% .^{1-4}$ As the bone marrow lacks lymphatics, bone marrow infiltration indicates vascular dissemination (stage IV disease). BM examination is usually done for clinical staging and BM involvement upgrades it to stage IV with a poorer prognosis. ${ }^{5-7}$ Extranodal $\mathrm{HL}$ is very rare and primary HL of marrow has an incidence of $0.25 \%{ }^{7}$ To the best of our knowledge, the present study is the largest study on HL, initially diagnosed on marrow including 36 cases, and highlights the role of BM examination in diagnosing HL based on its clinicopathological, histological, and immunohistochemical features.

\section{Materials and Methods}

This was a retrospective study done in a tertiary care center that included 36 cases of HL diagnosed initially on the BM from January 2012 to December 2020. The study was designed to emphasize the characteristic clinicopathological picture, i.e., pyrexia of unknown origin with cytopenias (primary outcome) in unsuspected cases of $\mathrm{HL}$ and create awareness on the requirement of lymph node biopsies with ancillary testing (secondary outcome) in such cases. All known cases $(n=157)$ of $\mathrm{HL}$, where BM examination was done for staging were excluded from the study. Clinical data, peripheral blood, and BM findings (as mentioned in the supplementary file) collected were retrospectively reviewed and analyzed. Under aseptic conditions, aspiration and biopsy were done from the posterior superior iliac spines. Six to 10 smears, each of peripheral smears, aspirates, and imprints were prepared, air dried, and stained. Smears were stained with Giemsa. BM biopsies done were decalcified, processed, and sections were stained with hematoxylin and eosin stain, and reticulin. Special stains such as acid-fast bacilli (AFB) were used wherever necessary. Based on the presence of large mononuclear or binucleate ReedSternberg (RS)-like cells in a polymorphous inflammatory background, HL was suspected and immunohistochemistry (IHC) was done on a fully automated immunostainer (X matrix Elite; BioGenex). The markers in the IHC panel included LCA/CD45, CD3, CD20, CD15, CD30, CD68, ALK, EMA, and PAX5. IHC was done on the marrow in 29 cases. In seven cases that had subsequent lymph node biopsy, the morphology of lymph node with IHC results was reviewed.

\section{Statistical Analysis}

For statistical analysis, Microsoft Excel 2019 was used and frequencies for each variable were calculated.

\section{Ethics}

The study was approved by the NIMS Institutional Ethics Committee with approval number of EC/NIMS/2705/2021, PBAC No. 1349/2021, dated 15.3.2021. The procedures followed were in accordance with the ethical standards of the responsible committee on human experimentation (institutional) and with the Helsinki declaration of 1964, as reviewed in 2013. Waiver of the informed consent form was obtained from the Ethics Committee due to the retrospective nature of the study.

\section{Results}

The study included 36 cases of HL diagnosed initially on the bone marrow in 9 years duration. In view of high-grade fever with associated bi/pancytopenias, all 36 cases were suspected as tuberculosis/lymphoma clinically and none of these cases had a prior diagnosis of HL.

There was a wide age distribution with a mean of 40 years ( $\pm 6.7,95 \%$ confidence interval $[\mathrm{CI}]$ ). There was a male predominance with a male to female ratio of $3: 1$, of which 27 were males and 9 were females. Three cases were positive for HIV with very low CD4 counts $\left(24,57\right.$, and 39 cells $\left./ \mathrm{mm}^{3}\right)$ and were on HAART therapy. Five cases were previously diagnosed as cases of tuberculosis and were on anti-tuberculous therapy (ATT). One case each was diagnosed with autoimmune hemolytic anemia, poliomyelitis, ileal perforation, digital gangrene, and mitral valve regurgitation. The clinical presentation of the 36 cases is depicted in - Table 1. Among "B" symptoms, fever (34/36) (94.4\%) was the most common symptom, followed by loss of weight (24/36) (66.7\%). As HL was not suspected before diagnosis on marrow, the clinical staging was not done. PET CT was done only in 14 patients due to financial constraints, of which 9 cases showed central lymphadenopathy (mediastinal, retroperitoneal, intra-abdominal), 2 cases had both central and peripheral nodes, 2 cases had space-occupying lesions, one each in liver and spleen and one case had no other masses or nodes anywhere else in the body. In cases $(n=22)$ where PET CT was not done, 15 cases had peripheral lymphadenopathy. Altogether, lymphadenopathy (peripheral or central or both) was seen in (26/36) $72.2 \%$ cases. Other findings included hepatomegaly (19/36) (52.7\%) and splenomegaly (18/36) (50\%). In 
Table 1 Clinical presentation in cases with bone marrow involvement by Hodgkin Lymphoma

\begin{tabular}{|c|c|c|}
\hline \multicolumn{2}{|c|}{ Clinical presentation } & $\begin{array}{l}\text { No. of cases }(\%) \\
(n=36)\end{array}$ \\
\hline \multicolumn{2}{|l|}{ Fever } & $34(94.4 \%)$ \\
\hline \multicolumn{2}{|l|}{ Cough } & $11(30.5 \%)$ \\
\hline \multicolumn{2}{|l|}{ Shortness of breath } & $8(22.2 \%)$ \\
\hline \multicolumn{2}{|l|}{ Abdominal pain } & $2(5.5 \%)$ \\
\hline \multicolumn{2}{|c|}{ Abdominal distension } & $5(13.9 \%)$ \\
\hline \multicolumn{2}{|l|}{ Vomiting } & $2(5.5 \%)$ \\
\hline \multicolumn{2}{|l|}{ Diarrhea } & $3(8.3 \%)$ \\
\hline \multicolumn{2}{|l|}{ Malena } & $1(2.7 \%)$ \\
\hline \multicolumn{2}{|l|}{ Loss of weight } & $24(66.7 \%)$ \\
\hline \multicolumn{2}{|l|}{ Loss of appetite } & $10(27.7 \%)$ \\
\hline \multicolumn{2}{|c|}{ Urinary tract infection } & $1(2.7 \%)$ \\
\hline \multicolumn{2}{|c|}{ Generalized weakness } & $11(30.5 \%)$ \\
\hline \multicolumn{2}{|l|}{ Jaundice } & $5(13.9 \%)$ \\
\hline \multicolumn{2}{|l|}{ Hepatomegaly } & $19(52.7 \%)$ \\
\hline \multicolumn{2}{|c|}{ Space-occupying lesion liver } & $1(2.7 \%)$ \\
\hline \multicolumn{2}{|c|}{ Splenomegaly } & $18(50 \%)$ \\
\hline \multicolumn{2}{|c|}{ Space-occupying lesion spleen } & $1(2.7 \%)$ \\
\hline \multirow[t]{3}{*}{ Lymphadenopathy } & Peripheral & $15(41.6 \%)$ \\
\hline & Central & $9(25 \%)$ \\
\hline & Both & $2(5.5 \%)$ \\
\hline \multicolumn{2}{|l|}{ Altered sensorium } & $5(13.9 \%)$ \\
\hline \multicolumn{2}{|l|}{ Pedal edema } & $1(2.7 \%)$ \\
\hline \multicolumn{2}{|l|}{ Pruritus } & $1(2.7 \%)$ \\
\hline \multicolumn{2}{|l|}{ Pallor } & $8(22.22 \%)$ \\
\hline
\end{tabular}

view of the presence of bi/pancytopenias, bone marrow aspiration and biopsy was performed in all cases and this was followed or accompanied by biopsy of the lymph node in only seven cases with peripheral lymphadenopathy. In patients who had only mediastinal or retroperitoneal lymphadenopathy, biopsies could not be obtained due to difficulty in accessing biopsy site.

The hematological profile of all cases is depicted in - Table 2. Cytopenia/s was seen in all cases with a mean number of cytopenias of $2.4 \pm 0.295 \% \mathrm{CI}$. All cases had anemia, of which $15 / 36$ cases (41.6\%) had normocytic normochromic anemia. Leucopenia was seen in 21/36 cases (58.3\%), of which two cases showed atypical lymphocytes on peripheral smear examination. Thrombocytopenia was seen in $26 / 36$ cases $(72.2 \%$ ) and $15 / 36$ cases (41.6\%) had pancytopenia.

Bone marrow aspirate was particulate in 24/36 cases (66.7\%), out of which smears were normocellular in 12/36 cases (50\%), hypercellular in $8 / 36$ cases (33.3\%), and hypocellular in 4/36 cases (16.6\%). Only one case showed suspicious mononuclear RS cells on BM aspirates and the rest of
Table 2 Hematological profile in cases with bone marrow involvement by Hodgkin lymphoma

\begin{tabular}{|c|c|c|}
\hline Parameter & Hematological profile & $\begin{array}{l}\text { No. of cases } \\
(\%)(n=36)\end{array}$ \\
\hline \multirow[t]{3}{*}{ Hemoglobin } & Mild anemia $(10-11 \mathrm{~g} / \mathrm{dL})$ & $18(50 \%)$ \\
\hline & Moderate anemia (7-9 g/dL) & $15(41.6 \%)$ \\
\hline & Severe anemia $(<7 \mathrm{~g} / \mathrm{dl})$. & $3(8.4 \%)$ \\
\hline \multirow{7}{*}{$\begin{array}{l}\text { Red blood } \\
\text { cells }\end{array}$} & Normocytic normochromic & $15(41.6 \%)$ \\
\hline & Anisopoikilocytosis & $19(52.7 \%)$ \\
\hline & Microcytes & $5(13.9 \%)$ \\
\hline & Macrocytes & $6(16.7 \%)$ \\
\hline & Tear drop cells & $2(5.5 \%)$ \\
\hline & Polychromatophils & $5(13.9 \%)$ \\
\hline & Nucleated RBCs & $2(5.5 \%)$ \\
\hline \multirow{2}{*}{$\begin{array}{l}\text { Total } \\
\text { leucocyte } \\
\text { count }\end{array}$} & Normal WBC count & $10(27.7 \%)$ \\
\hline & Leucopenia & $21(58.3 \%)$ \\
\hline \multirow{7}{*}{$\begin{array}{l}\text { Differential } \\
\text { leucocyte } \\
\text { count }\end{array}$} & Normal differential & $24(66.7 \%)$ \\
\hline & Relative neutrophilia & $1(2.7 \%)$ \\
\hline & Relative lymphocytosis & $4(11.11 \%)$ \\
\hline & Eosinophilia & $6(16.7 \%)$ \\
\hline & Monocytosis & $1(2.7 \%)$ \\
\hline & Shift to left & $4(11.11 \%)$ \\
\hline & Atypical lymphocytes & $2(15.5 \%)$ \\
\hline \multirow{2}{*}{$\begin{array}{l}\text { Platelet } \\
\text { count }\end{array}$} & Normal counts & $10(27.7 \%)$ \\
\hline & Thrombocytopenia & $26(72.2 \%)$ \\
\hline \multirow[t]{2}{*}{ Others } & Leucoerythroblastic picture & $1(2.7 \%)$ \\
\hline & Pancytopenia & $15(41.6 \%)$ \\
\hline
\end{tabular}

Abbreviations: RBC, red blood cell; WBC, white blood cell.

the cases were diagnosed only on trephine biopsy. Trephine imprints showed variable cellularity in 13/36 (36.1\%) cases.

Marrow cellularity on trephine biopsy varied from $50 \%$ to $90 \%$ with a mean of $68 \% \pm 4.8,95 \%$ CI. Diffuse involvement was seen in $24 / 36$ cases (66.7\%) and focal nodular aggregates were seen in $12 / 36$ cases (33.3\%). Marrow fibrosis was seen in $16 / 36$ cases (44.4\%) that included 12 cases with aparticulate aspirates and 4 cases with hypocellular aspirates. Reticulin condensation was variable from grade II to grade IV. Cases with diffuse involvement of marrow on biopsy showed acellular smears on imprint cytology with increased reticulin condensation of grade IV. Cases with focal nodular aggregates on biopsy showed predominantly variable cellularity on imprint cytology with a variable reticulin grading of grade II to grade III in involved marrow (-Fig. 1). Marrow necrosis was seen in 3/36 cases (8.4\%). Granulomas were seen in 8/36 cases (22.2\%), of which 1 case was HIV-positive. Stains were done for AFB and fungus and were negative (-Fig. 2).

The main diagnostic criterion of HL on marrow was the presence of large mononuclear or binucleate RS-like cells in a polymorphous inflammatory background that was seen in 


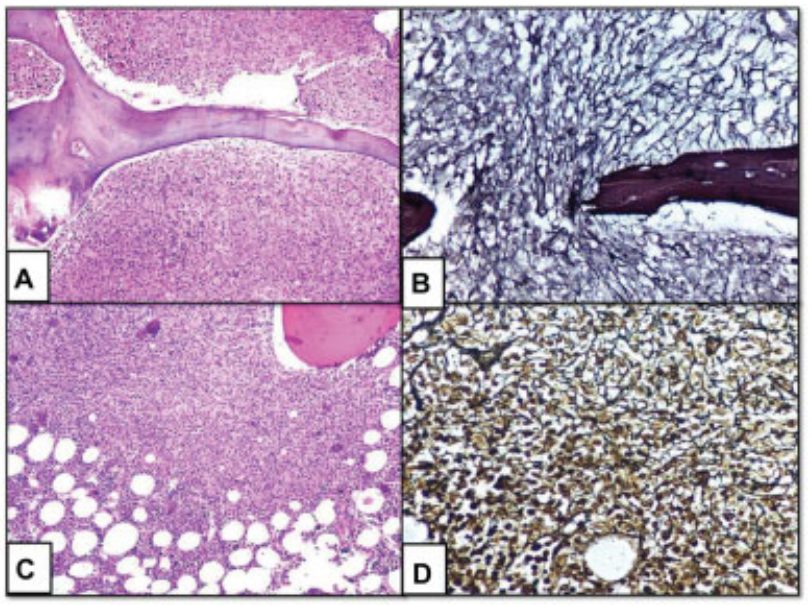

Fig. 1 Patterns of marrow involvement in HL. (A, B). Diffuse pattern. (A) Diffuse involvement on trephine biopsy $(\times 100, H \& E)$, (B) Increased reticulin condensation of grade IV ( $\times 400$, reticulin); (C, D). Focal pattern. (C) Focal nodular aggregates (above) with uninvolved marrow (below) on trephine biopsy $(\times 100, \mathrm{H} \& \mathrm{E})$, (D) Variable reticulin grading of grade III in involved marrow (above) and grade II in normal marrow (below) $(\times 400$, reticulin). $\mathrm{H} \& \mathrm{E}$, hematoxylin and eosin; $\mathrm{HL}$, Hodgkin lymphoma.

all 36 cases. Classical binucleated RS cells, as well as mononuclear Hodgkin cells, were seen in 26/36 cases (72.3\%), while mononuclear Hodgkin cells alone were seen in 10/36 cases (27.7\%). The background of the polymorphous population of inflammatory cells comprised lymphocytes, plasma cells, eosinophils, neutrophils, and histiocytes (-Fig. 3). IHC with CD30 and CD15 were done on trephine sections only in 29 cases. The $\mathrm{IHC}$ results on marrow were $\mathrm{CD} 30^{+} / \mathrm{CD} 15^{+}$in $(6 / 29)$ (20.7\%) cases, $\mathrm{CD}^{+} 0^{+} / \mathrm{CD}^{-} 5^{-}$in $(7 / 29)(24.1 \%)$ cases, and $\mathrm{CD} 30^{-} / \mathrm{CD} 5^{+}$in $(6 / 29)(20.7 \%)$ cases, and $\mathrm{CD}^{-} / \mathrm{CD}^{-} 5^{-}$in $10 / 29$ cases $(34.4 \%)$.

In cases $(n=10)$ with negative $\mathrm{IHC}$ results $\left(\mathrm{CD} 15^{-}, \mathrm{CD} 30^{-}\right.$, $\left.\mathrm{PAX}^{+}, \mathrm{CD}^{2} 0^{+}, \mathrm{ALK}^{-}, \mathrm{EMA}^{-}, \mathrm{CD}^{-}, \mathrm{CD}^{-} 5^{-}\right)$done on marrow,

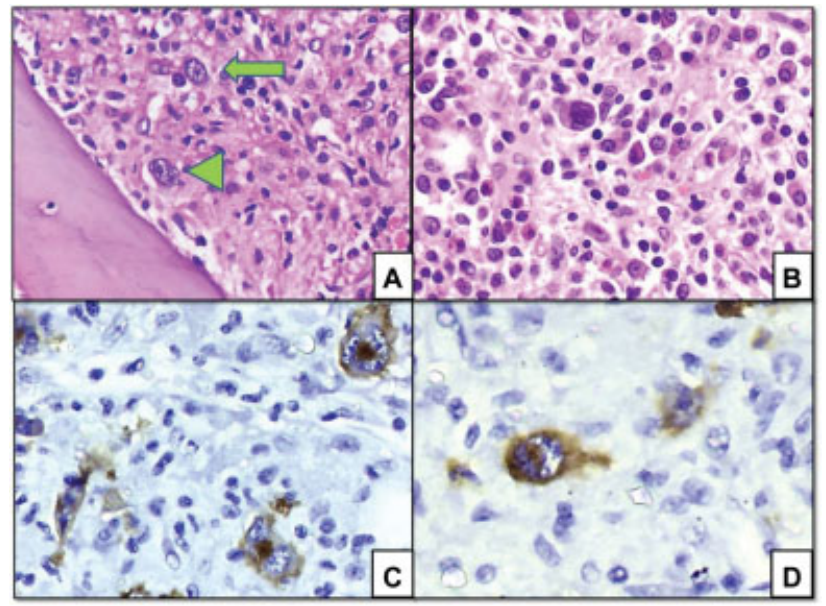

Fig. 3 Reed-Sternberg cells. (A) Binucleated (arrowhead) and mononucleated (arrow) RS cells. (B) Polymorphous background of eosinophils, plasma cells, and histiocytes $(\times 400, \mathrm{H} \& \mathrm{E}),(\mathrm{C}) \mathrm{IHC}$ with CD30 showing Golgi area positivity ( $\times 1000)$, (D) IHC with CD15 showing Golgi area positivity $(\times 1000)$. H\&E, hematoxylin and eosin; IHC, immunohistochemistry.

two cases had subsequent lymph node biopsy with positive $\mathrm{IHC}$ results $\left(\mathrm{CD} 15^{+}, \mathrm{CD}^{+} 0^{+}, \mathrm{PAX}^{+}, \mathrm{CD}^{+} 0^{+}, \mathrm{ALK}^{-}, \mathrm{EMA}^{-}, \mathrm{CD} 3^{-}\right.$, $\mathrm{CD}^{-} 5^{-}$) and were of mixed cellularity subtype. Of the remaining eight cases, three patients died and five got discharged against medical advice and were lost to follow-up.

In seven cases, IHC was not done on marrow because five cases had subsequent lymph node biopsies with positive IHC results, while two cases got discharged against medical advice and lost to follow-up. All seven cases with lymph node biopsy showed mixed cellularity HL, with IHC positivity for both CD15 and CD30. In total, there were 26/36 confirmed cases (72.2\%), of which only 1 case had no mass or lymph nodes anywhere else in the body even after extensive

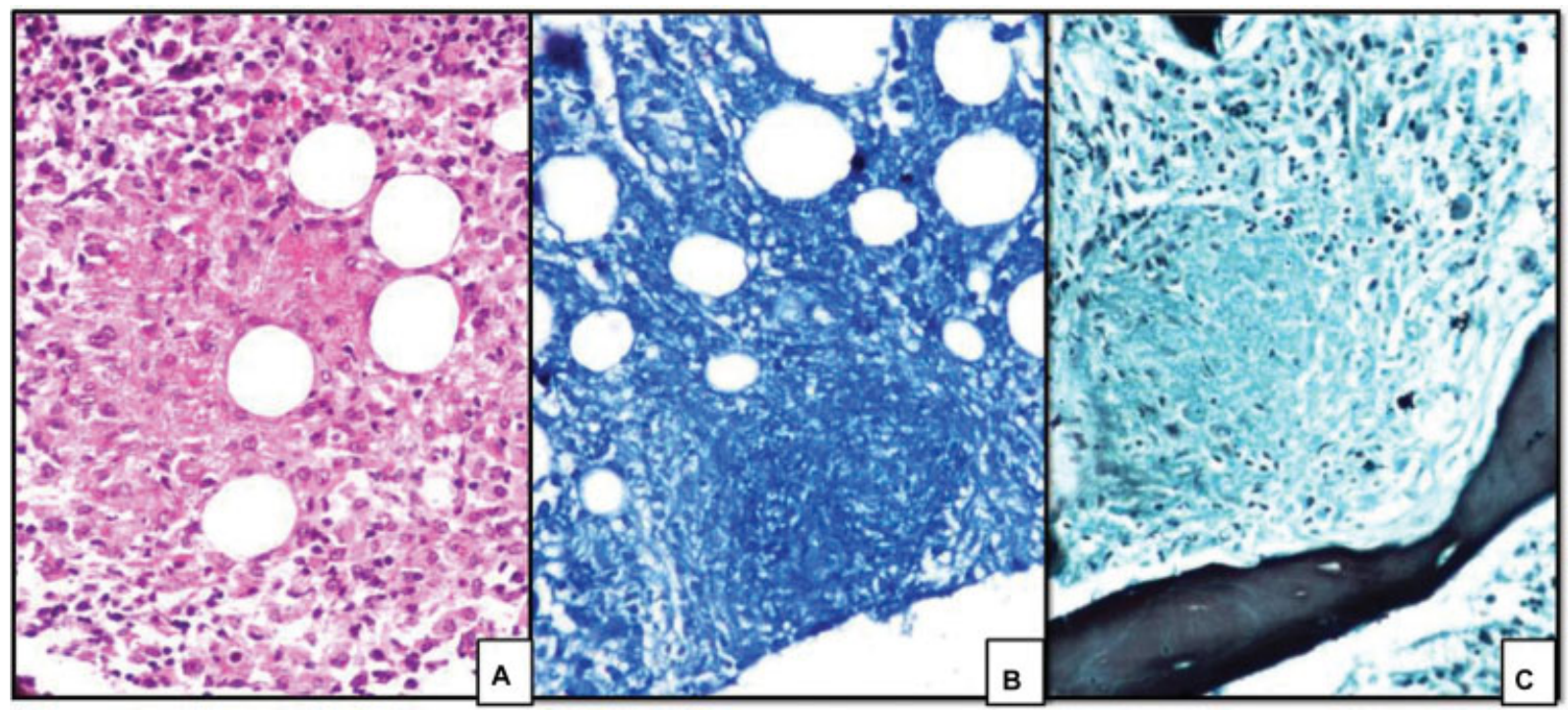

Fig. 2 Granulomas in marrow involved by HL. (A) Aggregates of epithelioid macrophages (X400, H\&E), (B) Negative for AFB ( $\times 100$, ZiehlNeelsen stain), (C) Negative for fungus ( $\times 100$, Grocott methenamine silver). AFB, acid-fast bacilli; H\&E, hematoxylin and eosin; HL, Hodgkin lymphoma. 
radiological workup and was finally diagnosed as primary $\mathrm{HL}$ of marrow.

Treatment strategies: Marrow diagnosis based on morphology alone indicates suspicion and needs IHC confirmation to start the treatment. All the cases of HL initially diagnosed on marrow with confirmed IHC results were treated as per the NCCN (National Comprehensive Cancer Network) recommendations with ABVD (adriamycin, bleomycin, vinblastine, and dacarbazine) regimen. In cases where IHC is inconclusive, a tissue diagnosis with positive IHC results is mandatory to start the treatment. If the nodes are not accessible, even an invasive procedure is attempted to retrieve the representative biopsy sample. In our study, only 26 (72.2\%) cases had a confirmed diagnosis of HL and were started on treatment. The remaining cases (10/36) (27.8\%) that were diagnosed only based on marrow morphology but had inconclusive IHC results, remained suspicious of HL. A confirmed diagnosis could not be made in these cases as three patients died of sepsis within a few days of diagnosis and the rest $(n=7)$ got discharged against medical advice and lost to further follow-up.

\section{Discussion}

BM studies are usually done as a part of the staging workup for HL because its involvement is considered as stage IV disease with poorer prognosis and reduced survival. ${ }^{1,5,6,8}$ When compared with non-Hodgkin lymphomas, HL involving marrow is relatively rare with an incidence of 3 to $18 \%{ }^{1,9-11}$ HL invariably arises in the lymph nodes, and primary extranodal HL is very rare. Isolated bone and bone marrow Hodgkin lymphoma is extremely rare, seen in less than $0.25 \%$ of cases, and very few case reports are reported in the literature. ${ }^{12-16}$ It is important to confirm whether extranodal involvement represents a primary manifestation or dissemination of systemic disease with a poor prognosis. ${ }^{7}$

Our study group comprised 36 cases that were first diagnosed on the marrow. They account for $18.7 \%$ of all HL cases $(n=193)$ that were diagnosed and underwent BM examination during the study period. The high number could be due to the longer duration of the study and only one case was finally diagnosed as primary HL of marrow, which accounted for $0.5 \%$ (1/193) of all the HL diagnosed in the study period. The rest of the cases (17/36) (18.2\%) were HL with secondary involvement of marrow but diagnosed initially on the marrow.

When clinicopathological features associated with HL ("B" symptoms) were studied, we noted that $94.4 \%$ of the cases presented with fever followed by loss of weight (66.7\%). Lymphadenopathy was seen in $55.5 \%$ of cases. The hematological profile revealed that $58.3 \%$ of cases had leucopenia, $72.2 \%$ of cases had thrombocytopenia, and $41.6 \%$ of cases had pancytopenia. Many studies revealed that the presence of "B" symptoms and cytopenias, especially leucopenia and thrombocytopenia, were frequently associated with BM involvement by HL. ${ }^{17-20}$

BM aspirates are comparatively of lesser diagnostic value in diagnosing $\mathrm{HL}$, as the involved marrow is difficult to aspirate due to marrow fibrosis. ${ }^{2,21}$ As the aspirates were aparticulate or hypocellular, there is no/limited role of flow cytometry in the diagnosis of HL involving marrow. In our study, only one case showed suspicious RS cells on aspirate. Variable cellularity on imprint smears is possibly due to marrow fibrosis and this should raise the suspicion of HL involving BM., ${ }^{4,22}$ We observed variably cellular imprint smears in $36.1 \%$ of cases. HL involving the marrow can be diffuse or focal, and an adequate length of BM needs to be sampled especially in cases with focal involvement. ${ }^{5}$ Diffuse involvement of BM was seen in $66.7 \%$ of our cases and focal nodular aggregates were seen in $33.3 \%$ of cases, similar to other studies. $^{17}$

Diagnosis of marrow involvement by HL is challenging, especially when there is no prior diagnosis on a lymph node or other site in the body. Knowledge of histomorphology in correlation with clinicopathological features is essential to diagnose HL on the marrow. ${ }^{23,24}$ As per the recommendations drawn at the Ann Arbor conference (1971), criteria to establish a marrow diagnosis of $\mathrm{HL}$ differ according to whether or not a tissue diagnosis of HL is already established. ${ }^{25}$ To diagnose HL initially on marrow without a tissue diagnosis, the presence of CD30- and/or CD15-positive "classic" binucleated RS cells in a polymorphous inflammatory background of lymphocytes, plasma cells, eosinophils, and neutrophils is required. An exception to this is that, in the nodular sclerosis subtype, the presence of "variant RS cells (lacunar cells)" in an appropriate cellular background is also sufficient to make the diagnosis. ${ }^{25}$

As per these diagnostic criteria, finding a classic binucleate RS cell is particularly challenging and wherever suspicious, we used IHC to confirm the diagnosis. In cases where tissue diagnosis is already made and bone marrow biopsy is done for staging, the criteria are less stringent, which include the presence of mononuclear Hodgkin cells in an appropriate cellular background. The presence of only a few large atypical cells (or) diffuse fibrosis with appropriate inflammatory cells is suggestive but not diagnostic of HL. In such suspicious cases, serial sections may reveal more diagnostic material and/or IHC is needed to confirm the diagnosis. ${ }^{25}$ Although CD30 is a specific marker for RS cells of HL, studies reveal that the sensitivity and specificity of CD15 in detecting cases of Hodgkin disease is $80 \%$ and $80.6 \%$, respectively. ${ }^{26}$ CD15 expression in HL differs between studies. ${ }^{18,19}$

In this study, immunophenotype of the RS cells on marrow $\mathrm{CD}_{30} / \mathrm{CD} 15^{+}$in $20.7 \%$ of cases, $\mathrm{CD} 30^{+} / \mathrm{CD} 15^{-}$in $24.1 \%$ of cases, and $\mathrm{CD}^{-} 0^{-} / \mathrm{CD} 15^{+}$in $20.7 \%$ of cases. Cases, where only CD30 was positive, showed positivity for PAX5 and negativity for CD3, CD45, ALK, and EMA, ruling out the possibility of anaplastic large cell lymphoma. CD68 was done to differentiate histiocytes from mononuclear RS cells, especially in cases where additional findings such as granulomas were seen.

Out of 10 cases with negative IHC results on marrow, 2 cases had subsequent lymph node biopsy and were diagnosed as HL. IHC on trephine sections often gives good results but occasionally, acid decalcification interferes with antigen retrieval due to the destruction of the antigenic epitopes by 
fixation and decalcification process used for BM biopsy specimens. ${ }^{27,28}$ This could be the possible explanation for the negative IHC results on marrow but positive on lymph nodes. So far, this is the largest study of HL diagnosed on marrow, where $72.2 \%$ (26/36) of cases had IHC confirmation, of which 19 cases (52.7\%) were confirmed on trephine sections and the rest on subsequent lymph node biopsies.

$\mathrm{HL}$ is a unique neoplasm that exhibits geographical variations in its histological subtypes as well as in the incidence of BM infiltration. ${ }^{3}$ Among the subtypes of HL, lymphocytedepleted HL has a higher frequency (54\%) of involving the marrow, followed by mixed cellularity HL (20\%). ${ }^{3}$ Nodular sclerosis HL rarely involves the marrow with an incidence of $5 \%{ }^{3}$ We observed that the seven cases in our study that had subsequent lymph node biopsies were diagnosed as mixed cellularity HL. Similar studies observed that BM involvement was more common in the lymphocyte-depleted subtype, followed by mixed cellularity. ${ }^{17,18,29}$

HL is one of the most common non-AIDS defining tumors that can occur in HIV-positive cases. ${ }^{5}$ Primary HL of the marrow is relatively rare but can be seen in HIV-positive individuals, and the secondary involvement of marrow by $\mathrm{HL}$ is relatively more common in HIV-positive patients. ${ }^{30}$ In our study, three cases were HIV-positive and all had lymphadenopathy. The term "isolated bone marrow HIV-associated Hodgkin lymphoma (IBM-HIV-HL)" refers to cases with BM involvement by HL in the absence of lymphadenopathy, even after extensive clinical and imaging evaluation. ${ }^{30,31}$ Because all three cases had lymphadenopathy, the term "IBM-HIVHL" does not apply to these cases. In all three cases, CD15and CD30-positive RS cells were seen on trephine sections. All three cases presented with pancytopenia and this could be secondary to marrow infiltration along with extensive stromal changes, such as fibrosis and necrosis were seen in HIV-positive patients. ${ }^{5}$

In our study, granulomatous inflammation was found in eight cases (22.2\%), of which one case was HIV-positive. Studies revealed that $\sim 9 \%$ of HL cases are accompanied by non-necrotizing epithelioid granulomas. ${ }^{32-34}$ The presence of epithelioid granulomas in cases with HL may reflect a host response to the tumor with favorable prognostic implications. ${ }^{34,35}$

\section{Limitations of the Study}

1. IHC confirmation of HL on marrow was not possible in all suspected cases as the results were altered by the decalcification process.

2. In cases with associated lymphadenopathy, subsequent lymph node biopsies were not available for all the cases as few of the cases had inaccessible central lymphadenopathy, few patients succumbed to death early and few got discharged against medical advice.

\section{Future Research Directions}

The current decalcification and fixation processes that are used for BM biopsy specimens interfere with antigen retriev- al due to the destruction of the antigenic epitopes. Future research should be aimed at developing an efficient decalcification process that does not affect the overall results.

\section{Conclusion}

Initial diagnosis of HL on marrow without a tissue diagnosis is very difficult and has stringent diagnostic criteria. So far, this would be the largest study in the literature describing 36 clinically unsuspected cases of HL that were diagnosed initially on the marrow. In cases presenting with fever and cytopenias where BM examination is done, the presence of RS cells in a polymorphous cell background should always raise the suspicion of HL. Bone marrow biopsy is preferable over aspiration in such cases due to associated secondary marrow fibrosis, and IHC plays a major role in the confirmation of diagnosis. The study concludes that the knowledge of clinical and histological features of HL can aid in the diagnosis of these lesions on the marrow in clinically unsuspected cases. This study also shows that the presence of "B" symptoms or cytopenias is associated with the highest risk of BM involvement by HL. When these risk factors are coexistent, the likelihood of having BM involvement is further increased.

Funding

None.

Conflicts of Interest

None declared.

\section{References}

1 Shi YF, Li XH, Song YQ, Song WW, Lai YM. Involvement of bone marrow in lymphoma: pathological investigation in a singlecenter from northern China. Int J Clin Exp Pathol 2015;8(06): 7102-7111

2 Howell SJ, Grey M, Chang J, et al. The value of bone marrow examination in the staging of Hodgkin's lymphoma: a review of 955 cases seen in a regional cancer centre. Br J Haematol 2002;119 (02):408-411

3 Nadeem M, Naqi N, Hussain I, Khattak J, Ahmed R, Khan B. Frequency of bone marrow involvement in Hodgkin's lymphoma on first presentation. J Coll Physicians Surg Pak 2009;19(12): 768-771

4 Subramanian R, Basu D, Badhe B, Dutta TK. Role of bone marrow trephine biopsy in the diagnosis of marrow involvement in Hodgkin's disease. Indian J Pathol Microbiol 2007;50(03): 640-643

5 Franco V, Tripodo C, Rizzo A, Stella M, Florena AM. Bone marrow biopsy in Hodgkin's lymphoma. Eur J Haematol 2004;73(03): 149-155

6 Swerdlow SH, Campo E, Harris NL, et al. WHO Classification of Tumours of Haematopoietic and Lymphoid Tissues. Lyon: IARC; 2008

7 Zhang Q-Y, Foucar K. Bone marrow involvement by hodgkin and non-hodgkin lymphomas. Hematol Oncol Clin North Am 2009;23 (04):873-902

8 Gonçalves Mde C, de Paula HM, Linardi Cda CG, et al. Dealing with bone marrow biopsies in the staging of classical Hodgkin lymphoma: an old issue revisited in the (18)F-fluorodeoxyglucosepositron emission tomography era. Leuk Lymphoma 2015;56 (10):2883-2888 
9 Gaudio F, Pedote P, Niccoli Asabella A, et al. Bone involvement in Hodgkin's lymphoma: clinical features and outcome. Acta Haematol 2018;140(03):178-182

10 Chauhan K, Jain M, Shukla P, Grover RK. Bone marrow involvement in Hodgkin's lymphoma: data from a cancer hospital. Clin Cancer Investig J 2016;5:516-520

11 Laurent C, Arber DA, Johnston P, Fend F, Zamo A, Attygalle AD. Diagnosis of classic Hodgkin lymphoma on bone marrow biopsy. Histopathology 2020;76(07):934-941

12 Guermazi A, Brice P, de Kerviler E, et al. Extranodal Hodgkin disease: spectrum of disease. Radiographics 2001;21(01): 161-179

13 Eustace S, O'Regan R, Graham D, Carney D. Primary multifocal skeletal Hodgkin's disease confined to bone. Skeletal Radiol 1995; 24(01):61-63

14 Fried G, Ben Arieh Y, Haim N, Dale J, Stein M. Primary Hodgkin's disease of the bone. Med Pediatr Oncol 1995;24(03):204-207

15 Lamba B, Talreja VT, Sudeep V, Mittal S. A case report of primary Hodgkin's disease of bone marrow. Sahel Med J 2015;18(02): 87-88

16 Munker R, Harenclever D, Brosteanu O. Bone marrow involvement in Hodgkin's disease: An analysis of 135 consecutive cases. German Hodgkin's lymphoma study group. J Clin Oncol 1996; 14:682-683

17 Sudalaimuthu M, Basu D. Clinicopathological features of bone marrow infiltration in Hodgkin lymphoma. Should bone marrow staging be done only in high risk patients? Turk Patoloji Derg 2017;33(02):129-133

18 Vassilakopoulos TP, Angelopoulou MK, Constantinou N, et al. Development and validation of a clinical prediction rule for bone marrow involvement in patients with Hodgkin lymphoma. Blood 2005;105(05):1875-1880

19 Kini JR, Suresh PK, Sinha R, Sahu KK, Kumar S, Prasad K. Value of bone marrow examination in Hodgkin lymphoma: report of three cases with review of literature. J Cancer Res Ther 2012;8(03): 457-459

20 Durosinmi MA, Mabayoje VO, Akinola NO. A review of histology of bone marrow trephine in malignant lymphomas. Niger J Med 2003;12(04):198-201

21 Ananthamurthy A, Kurien A, Ramnarayan K. The bone marrow in Hodgkin's disease-a two year study. Indian J Cancer 2000;37(04): 173-183

22 Rappaport H, Berard CW, Butler JJ, Dorfman RF, Lukes RJ, Thomas LB. Report of the Committee on Histopathological Criteria Con- tributing to Staging of Hodgkin's Disease. Cancer Res 1971;31 (11):1864-1865

23 Kar R, Dutta S, Tyagi S. Clinically unsuspected Hodgkin's lymphoma diagnosed primarily from bone marrow trephine biopsy: report of six cases. Indian J Pathol Microbiol 2008;51(02): 186-189

24 Dholaria B, Alapat D, Arnaoutakis K. Primary bone marrow Hodgkin lymphoma in an HIV-negative patient. Int J Hematol 2014;99(04):503-507

25 Lukes RJ. Criteria for involvement of lymph node, bone marrow, spleen, and liver in Hodgkin's disease. Cancer Res 1971;31(11): 1755-1767

26 Hall PA, D'Ardenne AJ. Value of CD15 immunostaining in diagnosing Hodgkin's disease: a review of published literature. J Clin Pathol 1987;40(11):1298-1304

27 Sah SP, Matutes E, Wotherspoon AC, Morilla R, Catovsky D. A comparison of flow cytometry, bone marrow biopsy, and bone marrow aspirates in the detection of lymphoid infiltration in $B$ cell disorders. J Clin Pathol 2003;56(02):129-132

28 Athanasou NA, Quinn J, Heryet A, Woods CG, McGee JO. Effect of decalcification agents on immunoreactivity of cellular antigens. J Clin Pathol 1987;40(08):874-878

29 Horváth E, Mezei T, Pávai Z, et al. Diagnostic and differential diagnostic criteria of lymphoid neoplasms in bone marrow trephine biopsies: a study of 87 cases. Rom J Morphol Embryol 2009;50(03):399-406

30 Shah BK, Subramaniam S, Peace D, Garcia C. HIV-associated primary bone marrow Hodgkin's lymphoma: a distinct entity? J Clin Oncol 2010;28(27):e459-e460

31 Ponzoni M, Fumagalli L, Rossi G, et al. Isolated bone marrow manifestation of HIV-associated Hodgkin lymphoma. Mod Pathol 2002;15(12):1273-1278

32 Al-Maghrabi JA, Sawan AS, Kanaan HD. Hodgkin's lymphoma with exuberant granulomatous reaction. Saudi Med J 2006;27(12): 1905-1907

33 Aggarwal P, Sharma M, Nimbran V, Kaur K. Hodgkin lymphoma with granulomas. Demystifying the dilemma. Ann Pathol Lab Med 2018;5(04):C72-C74

34 Du J, Zhang Y, Liu D, Zhu G, Zhang Q. Hodgkin's lymphoma with marked granulomatous reaction: a diagnostic pitfall. Int J Clin Exp Pathol 2019;12(07):2772-2774

35 O'Connell MJ, Schimpff SC, Kirschner RH, Abt AB, Wiernik PH. Epithelioid granulomas in Hodgkin disease. A favorable prognostic sign? JAMA 1975;233(08):886-889 